\title{
Temporal and spatial variation of hydrochemical contamination in a former radium-uranium tailing dam as a result of environmental remediation field works
}

\section{Sofia Barbosa ( $\sim$ SVTB@FCT.UNL.PT)}

FCT-NOVA School of Science and Technology https://orcid.org/0000-0002-6233-2970

\section{Mariana Pinto}

FCT-NOVA

\author{
J. A. Almeida \\ FCT-NOVA \\ E. Carvalho \\ EDM, S.A. \\ C. Diamantino \\ EDM. S.A.
}

\section{Original Manuscript}

Keywords: Tailings, hydrodynamic flow paths, spatio-temporal hydrochemical trends, contamination plume migration, K-means of PCA scores

Posted Date: February 2nd, 2021

DOl: https://doi.org/10.21203/rs.3.rs-161188/v1

License: (c) (1) This work is licensed under a Creative Commons Attribution 4.0 International License. Read Full License 


\section{Abstract}

The main objective of this work was to understand the evolution of water quality within a tailings dam of a former radium-uranium mining site as a response to environmental remediation works. For this, results of numerical groundwater modeling were combined with multivariate hydrochemical trend analysis derived multivariate Principal Component Analysis and K-means clustering analysis. Numerical groundwater models were developed with the aim of detecting the main flow paths inside the tailings dam and across its bordering. These models allowed the identification of the hydrodynamic flows in the area that are most likely to be directly responsible for relevant hydrochemical exchanges in time. The spatial evolution of the contamination plume in time was mapped considering a cumulative interpretation that integrates all the hydrochemical indicators simultaneously through multivariate and clustering analysis. Resulting hydrochemical maps were superposed with the flow paths identified from modelling allowing to conclude that the contamination plume migrates within the tailings in the dependence of the main water flow paths that percolates within the tailings dam due to the existence of old shafts and old pre-existing streamlines located underneath the tailings dam. The methodology adopted allowed the verification of a general improvement in groundwater quality with a spatial reduction of the contamination plume within the tailings dam.

\section{Introduction}

The case study relates to an old radium-uranium tailings dam located in the Central Region of Portugal. Since 2002, a Water Quality Monitoring Plan (WQMP) has been in place at this site by EDM, a Portuguese state-owned company (EDM, 2011). From 2005 to 2007, EDM carried out environmental remediation works at this old tailings dam. The site in question was subject to a relevant environmental rehabilitation project in order to mitigate the radiological impacts, control leachate generation and chemical contamination dispersion, as well as to create the necessary security conditions for the geomechanical stability of slopes. The study considers the time-series results of this WQMP for the period between 2002 and 2016, which comprises data from pre to post environmental remediation works. It is important to mention that for this period of time, the developed WQMP allowed the identification by the operator and the responsible authorities of the main hydrochemical indicators to be considered for the control of water contamination derived from the talings dam, which were: $\mathrm{pH}$, Conductivity $(\mu \mathrm{S} / \mathrm{cm})$, eH, total uranium (p.p.b.), radium-226 $(\mathrm{mBq} / \mathrm{l})$, sulphate $(\mathrm{mg} / \mathrm{l})$, chloride $(\mathrm{mg} / \mathrm{l})$, manganese $(\mathrm{mg} / \mathrm{l})$ and calcium $(\mathrm{mg} / \mathrm{l})$ decrease in consequence of $\mathrm{pH}$ increment. The study and selection of these hydrochemical indicators is therefore out of the scope of the present study.

Groundwater modeling outputs generated for the area of the tailings dam and its interpretative results were combined with the results of principal component and K-means clustering analysis of hydrochemical data, in order to understand flow paths dynamics within the tailings dam and its implications on groundwater quality changes in the consequence of the environmental remediation works.

The first phase of this study was the development of a numerical groundwater model for the tailings dam site. Equivalent continuum modeling with single porosity (Jeong and Lee, 1999; Berkowitz B. et al., 1998; 
Samardzioska and Popov, 2005; Chen et al. 2018; Yan X. et al., 2019) was considered. Each identified media was assumed to be equivalent to a homogenous porous media with groundwater flow governed by Darcy's law. For the modeling process, local variations of porosity and hydraulic conductivity were assumed for each media. These variations were considered in the input grids of the model according to the local characteristics of lithology, granulometry, weathering, joint and faulting which have direct implications on potential flow path generation and on local modifications on potentiometric head surface (Pinto, 2016). Groundwater modeling was considered with a maximum depth of sixty meters below the base of the dam. Percolation circuits, main inflow and outflow paths generated through the tailings dam and hydrodynamic changes verified between pre and post-remediation stages were identified.

The focus of the second stage of this study was the analysis and interpretation of hydrochemical data related with the piezometers and water shafts installed in the dam and in its surroundings. These structures are related with the WQMP that was initiated in 2002 by the operator and has continued to the present days (EDM, 2011; Diamantino et al., 2016; Zhang et al., 2017). In contamination problems, detection and estimation of statistical tendencies and patterns may be a complex process especially in situations where environmental conditions change, as is this case. Seasonality factors, data asymmetry, moderate and severe outliers, missing data, are examples of situations that often occur and that may impede interpretations, statistic processing and data trend detection (Hirsch et al., 1982; Hirsch and Slack, 1984; Kundzewicz and Robson, 2004; Boyacioglu and Boyacioglu, 2008; Wahlin and Grimvall, 2008; Chandler and Scott, 2011; Mozejko, 2012, Anghileri et al., 2014, Monteith et al 2014, Cooper et al, 2000; Voudouris et al., 2000). Uncertainty generated by noise in the observed data hampers the detection of possible trends and the means that are necessary for accurate statistical methods (Mozejko, 2012).

In our work, distinct subsets of quarterly frequency hydrochemical data were considered accordingly with each monitoring piezometer (that is, piezometers numbers 1, 2, 3, 5, 6, 7, 9, 10 and 11) and for three distinct periods of time T1, T2 and T3, where T1 aggregates hydrochemical data for each piezometer before environmental remediation works (from 2002 to 2005), T2 aggregates the data immediately after environmental remediation works (from 2008 until 2010), and, T3 aggregates data after the remediation works for more significant period of time (from 2015 to 2016). An interpretation of the hydrochemical quality evolution for each piezometer (1, 2, 3, 5, 6, 7, 9, 10 e 11) along time (T1, T2 and T3) was developed. According to the available data for each piezometer at each time-period, 24 subsets (that is, 3 periods of time per each piezometer) were established and considered for statistical interpretation: 1T1, 1T2, 2T1, 2T2, 2T3, 3T1, 3T2, 3T3, 5T1, 5T2, 5T3, 6T1, 6T2, 6T3, 7T2, 7T3, 9T1, 9T2, 9T3, 10T1, 10T3, 11T1, 11T2 and 11T3. For each subset, the hydrochemical indicators $\mathrm{pH}$, uranium total mass concentration (referred as Utotal or total uranium) (ATSDR, 2011; Keith et al., 2014; Diamantino et al., 2016), radium-226 (Ra226), sulphate (SO4), chloride ( $\mathrm{Cl})$, manganese $(\mathrm{Mn})$ and calcium $(\mathrm{Ca})$ were considered for multivariate and cluster statistical analysis, more specifically Principal Component Analysis (PCA) and K-means clustering method (KMC) (Voudouris et al., 2000, Yeung et al., 2001; Swanson et al., 2001; Ding and He, 2004; Koonce et al., 2006; Templ et al. 2008; Thyne et al., 2008; Ledesma-Ruiz et al., 2015; Machiwala and Madan, 2015; Mandel et al., 2015, Peng K., 2015; Li and Gao, 2018; Sotomayor et al., 2018; Marín Celestino et al., 2019, Helena B. et al., 2020). PCA and KMC were selected to develop statistical analysis of the space-time data. 
Mapping of PCA scores (PCs) was performed. Subsequently, analysis of PCs with KMC was performed. The PCs were considered firstly for subsequent KMC analysis and secondly to develop interpretative spacetemporal maps. Each cluster obtained with KMC analysis of the PCs represents a specific hydrochemical profile that was considered to verify the evolution of groundwater quality over time, at each one of the piezometers. As it will be evident, the interpretation of PCs with KMC provides a better understanding of the spatio-temporal trends, allowing more synthetic and, therefore, much easier interpretations when observations and datasets are complex and difficult to interpret. Also, being PCA and KMC multivariate statistical analysis procedures, its consideration allows the cumulative integration of the multiple hydrochemical indicators at the same time in one single analysis.

Finally, location of the distinct hydrochemical profiles (clusters) were crossed with the groundwater modelling results enabling a better understanding of the inner hydrodynamics of the tailings dam and its direct implication on contamination plume changes over time. Relations between different flow paths located inside and beneath the tailings dam and its spatial correspondence to hydrochemical evolution through time (T1, T2 and T3) were possible to be performed.

\section{Materials And Methods}

\subsection{The old tailings dam and its hydrogeological conceptual model}

The deposition of tailings in place started in early 1910s and finished in 1988. In the initial years it was related to production of radium concentrate. Subsequently, after the Second World War, the production changed to uranium concentrate. The tailings deposited have therefore high heterogeny regarding its mineralogical and geochemical composition. According with Unified Soil Classification System, USCS (Directive ASTM D2487-11; Howard, 1986), these tailings have a high granulometric diversity, ranging from clays, silts, silty-clay, clay loam and fine to medium sands. According to local geological and geophysical studies promoted by the operator (EDM, 2011), the rock mass that underlays the dam is a granite with two major areas of distinct weathering and joint degrees (ISRM, 1981). Major faults throughout the granite are present and are possibly the main conduits for water circulation beneath the tailings dam as they are linked to a local riverside. Also, old mine shafts installed within the tailings have acted as conduits for water circulation between the surface of the dam and its interior and, in some cases, the underling rock mass. For several years, before de remediation works, these mining structures promoted the connectivity with atmosphere and oxidation phenomena.

The tailings dam is located at the Iberian or Hesperian Massif and was constructed over a monzonitic, twomica and predominantly biotitic hercynian granite of late carbonic age.

According with previous characterization studies developed with the support of the operator (EDM, 2011), the area mainly comprises of two aquifer systems. The first and most superficial one is three to six metres thin and hypodermic in nature as it is composed of residual soil that results from the weathering of the granite. Here, the groundwater flow is performed by a "porous" type media and develops accordingly with local porosity and permeability. The second aquifer is semi-confined and underlies the first. It has a very 
distinct anisotropic hydraulic behaviour once it is formed by the granite rock matrix. The groundwater flow is primarily directly dependent on fracture and on its spatial density, interconnectivity, filing and aperture characteristics. Interconnectivity between the two aquifers is expected to be difficult because of the clayed nature of the residual top soil of the first layer which may act in some places as a geological barrier. Infiltration and leakage is mainly present in areas where fractures or faults facilitate hydraulic connectivity between the two aquifers.

In the area that underlies the tailings dam, prospecting and geophysical site investigation studies allowed the detection of local drainage that can be generated from 3 to 6 until 13 to 14 meters deep, in direct dependence to the local fracture conditions. Figure 1 presents a general conceptual model for the study area that includes the water potential surface of the complex system composed by the tailings and the hypodermic aquifer that underlays the tailings dam. It includes the main water inflow and outflow in the area of the dam and the preferential water flows inside de tailings deposit (Fig. 1). It is to be referred that a local inflow stream that surrounds the West side of the tailings dam has a significant importance in local groundwater flow percolation. Before environmental remediation works, riverside embankments on the East side have worked as main receptors of the seepage that is generated in the tailings dam and percolate through the preferential flow streamlines. The outflow is mainly formed by the groundwater that circulates in the hypodermic aquifer with the water inputs that circulates through the tailings and are conducted downwards (seepage). In its turn, this outflow results in preferential seepage to the second semi-confined aquifer where the rock massive is more fractured and in local influx on the riverside of the local river (Fig. 1).

Before the mentioned environmental remediation works, the superficial water and groundwater at the tailings site offered a very poor quality. Besides the radiological atmospheric effects, significant local impacts in hydrological and groundwater systems were also present in the consequence of this old mining processing structure.

The priority objectives of the environmental remediation work fields were to confine the waste deposits, circumscribing the dispersion of sources of contamination and the levels of radiation caused by them, as well as establishing the safety conditions associated with the geomechanical stability of slopes. Landfill was modelled and re-profiled with the purpose of the geomechanical stabilization of the slopes and a drainage system along with a multi-layer covering system was installed.

\subsection{Groundwater modeling}

The groundwater models were performed with the freeware version of the Processing Modflow for Windows, PMWIN 5.3.1 (Chiang and Kinzelbach, 1998). PMWIN, Processing Modflow for Windows, version 5.3, is included in the book "3D-Groundwater Modeling with PMWIN" published by Springer-Verlag (Chiang and Kinzelbach, 2001). PMWIN is an integrated simulation system for modeling groundwater flow and transport processes. This program is based on the MODFLOW code developed by the US Geological Survey (McDonald and Harbaugh, 1988). The equations of the numerical models are solved by the finite difference method. For the case study, two models were tested (1) a first stage model for the tailings dam situation before environmental remediation works and (2) a second stage model which considers the tailings dam situation after environmental remediation works. In both cases two layers were considered for the models: 
a) a $1 .{ }^{\text {st }}$ layer for the tailings materials and b) a $2 .{ }^{\text {nd }}$ layer that represents the granite underlying the tailings dam.

Before the simulations, an exploratory data analysis (EDA) of the measured heads of the piezometers was performed in order to achieve a good understanding of the hydraulic behaviour and water flow within the tailings dam. EDA is a graphical technique that allows an advanced visual examination of the data, as it is a key component of any statistical analysis (Mozejko, 2012; Kundzewicz and Robson, 2004; Chandler and Scott, 2011). Figure 1 includes a view of the grid developed for numerical modeling and its boundary conditions.

The grid dimension and its geometry (Fig. 1) were selected in accordance with the tailings dam dimensions, the main area of interest for the study and the major local geological heterogeny that have unquestionable implications to local groundwater flow generation and propagation. The inflows considered for the numerical models were superficial recharge and circulation of groundwater in the underlying granite that comes into the tailings dam area, especially from the West and Norwest site of the dam (Fig. 1). Recharge rate was calculated in accordance with local conditions of soil occupation and vegetation type along with the calculated site water balance. The boundary of the numerical models are the physical frontiers of the tailings dam and the old mining shafts and piezometers (Fig. 1) which, over time, have functioned as locals of contact between the deposited materials in the dam, the atmosphere and the underlying hydrogeological media. For the second stage model, that is, after environmental remediation works, the recharge rate in the area of the tailing dam was considered to be " 0 " (zero) once this mining structure was covered with an impermeable multi-layer system. The two layers were simulated as aquifers of the type "Equivalent Continuum Porous Media" (EPM) (Durlofsky, 1991; Scanlon et al., 2003; Samardzioska and Popov, 2005; Blessent et al., 2014; Khoei et al., 2016). In the first stage model, an unconfined layer was considered for tailings dam representation and a semi-confined layer was considered for the underlying residual soil and the rock granite. In the second stage model, in the consequence of environmental remediation process, the tailings dam was modelled as a confined layer. This confined layer represents the tailings dam covered by a multi-later system and completely recovered. The underlying residual soil and rock granite were modelled as a semi-confined layer like in the first stage model. Distinct local porosity and hydraulic permeability conditions were tested and simulated for the two layers and for the two models. In the second layer some local differences were considered regarding porosity and hydraulic conductivity, according to more or less expected weathering and fracture conditions of the granite and in accordance with the recognized fault, river and stream locations. The grid cells that are intersected by rivers or that have preferential groundwater circulation across fracture were modelled as small local "channels" considering a very high porosity index (near 1 ) and high hydraulic conductivity ranges. Differences between the (real) measured heads and the simulated heads were the main criteria considered during calibration procedure of the two stage models. Porosity and hydraulic conductivity were the input parameter-values ("p-number" values in PMWIN terminology) considered for calibrating the numerical models.

\subsection{PCA and K-Means cluster analysis}

The multivariate statistical analyses were performed using R software "R Project for Statistical Computing" (Hothorn and Everitt, 2005, 2017; R Core Team, 2013; Rahlf, 2017). PCA and KMC were applied to 
hydrochemical data subsets (Ding and He, 2004; Koonce et al., 2006; Machiwala and Madan, 2015; Sotomayor et al., 2018). Quantitative variables of the analysis were the hydrochemical indicators of contamination $\mathrm{pH}$, Utotal, Ra226, SO4, Cl, Mn and Ca.

PCA can be done by eigenvalue decomposition of a data covariance or correlation matrix or singular value decomposition of a data matrix. The number of the newly generated variables, the principal components, is equal to the smaller of the number of original variables minus one. With this procedure, the dimensionality of the data is reduced and interpretations are facilitated. PCA is mostly used as a tool in EDA and multivariate statistical analysis and also to visualize genetic distance and relatedness between data observations and quantitative or qualitative variables (Santos et al., 2010; Zhang et al., 2012; Machiwala and Madan, 2015; Wuttichaikitcharoen and Babel, 2014; Selvakumar et al., 2017). The results of a PCA are usually discussed in terms of component scores, sometimes called factor scores, that is, the transformed variable values corresponding to a particular data point and loadings which are the weight by which each standardized original variable should be multiplied to get the component score. PCA aims to construct a low-dimensional subspace based on a set of principal components (PCs) to approximate all the observed samples in the least-square sense (Pearson, K. 1901; Kim and Kim, 2012]. Due to the quadratic loss used, PCA is notoriously sensitive to corrupted observations (outliers) and the quality of its outputs can suffer severely in the face of even a few outliers (Kim and Kim, 2012). For this, and in order to ensure a better statistical significance of the selected data series, it was decided during the pre-processing data stage to eliminate the strongest outliers. In our study, PCA was then used to the selected data sets for unsupervised dimension reduction of data. Package FactoMineR of $\mathrm{R}$ was used (Le et al., 2008). PCA for the hydrochemical variables $\mathrm{pH}$, Utotal, $\mathrm{Ra} 226, \mathrm{SO} 4, \mathrm{Cl}, \mathrm{Mn}$ and $\mathrm{Ca}$ was performed. The data was reduced into three main components which describes differences in the concentrations of Utotal, $\mathrm{Ra} 226, \mathrm{SO} 4 \mathrm{Cl}, \mathrm{Mn}$ and Ca according with $\mathrm{pH}$ conditions at the different piezometers $(1,2,3,5,6,7,9,10$ e 11) and at distinct time intervals T1, T2 and T3. The three PCs describes differences in groundwater compositions, in accordance with different $\mathrm{pH}$ conditions that result from modifications in tailings composition and/or from changes in drawdown and/or hydrodynamics conditions in groundwater flow.

The PCs scores were then considered for a subsequent $\mathrm{KMC}$ analysis. $\mathrm{KMC}$ is a method that is popular for cluster analysis. $\mathrm{K}$-means clustering aims to partition $\mathrm{n}$ observations into $\mathrm{k}$ clusters, in which, each observation belongs to the cluster with the nearest mean, serving as a prototype of the cluster. It is an unsupervised clustering technique commonly used. This procedure results in partitioning of the data space into Voronoi cells. Dissimilar and contrasting expert opinions may be found in related literature depending on the order of analysis that was chosen between PCA and KMC, and the effectiveness of using PCA scores to subsequent KMC. "PCA before KMC" or "KMC before PCA". For the case of "PCA before KMC", PCA is applied before clustering analysis in order to reduce dimensionality and in order to facilitate the visualization of the main relevant clusters. According to Ding and He (2004), PCA variables are the continuous solutions to the discrete cluster membership indicators for KMC. Yeung et al. (2001), for instance, showed that clustering with the PCA scores instead of the original variables does not necessarily improve cluster quality. These authors concluded inclusively that the first PCA variables (which contain most of the variation in the data) may not necessarily capture most of the cluster structure. In our work, we 
compute KMC after PCA. KMC was performed to group the data observations into distinct major clusters. Tests were performed for 4, 5, 6 and 7 clusters. Distinct cluster groups represents different hydrochemical profiles. Subsequently, the space-time data subsets $(1 T 1,1 T 2,2 T 1,2 T 2,2 T 3,3 T 1,3 T 2,3 T 3,5 T 1,5 T 2,5 T 3$, 6T1, 6T2, 6T3, 7T2, 7T3, 9T1, 9T2, 9T3, 10T1, 10T3, 11T1, 11T2 and 11T3) were classified according with these hydrochemical profiles. Also, with this procedure, it was also possible to made an interpretation of the hydrochemical quality evolution for each piezometer (1, 2, 3, 5, 6, 7, 9, 10 e 11) along time (T1, T2 and T3). Environmental quality evolution verified in groundwater that percolates within the tailings dam were achieved considering a multivariate interpretational approach once all the hydrochemical variables are considered simultaneously.

For better visualization and spatial interpretation, PCA scores were mapped using the geostatistical procedure of kriging.

\subsection{Map interpretation of simulated flow path and hydrochemical profiles}

At the final stage of the study, a mapping interpretation procedure was applied with the aim to evaluate the spatial evolution of groundwater quality in the area of the tailings dam. Results of groundwater quality evolution in each piezometer, derived from previous multivariate statistical analysis, were spatially overlapped with the locations of preferential percolation flow paths of the simulated groundwater numerical models. With this procedure, it was possible to identify preferential percolation paths of the contamination plume in time and in the consequence of the environmental remediation field works that were performed.

\section{Results And Discussion}

\subsection{Groundwater modeling}

Calibration and stability of the numerical models were achieved after a series of tests where hydraulic conductivity and porosity were the main "p-numbers" (calibration parameters) considered which were modified and adjusted in order to achieve the closest possible numerical approximation between the real and the simulated piezometric heads. The achieved results were satisfactory considering that a groundwater model for a fractured rock matrix was simulated as an EPM and also considering the high variability and uncertainty of composition, porosity and hydraulic conductivity of the materials in the tailings deposit. Figure 2 presents an exemplification of the best modeling results achieved for pre and postremediation scenarios. Regarding the results presented in Fig. 2, it is relevant to emphasize that the main hydraulic gradient and flow path presents are consistent with the local old preferential streamlines that are located beneath the tailings dam (Fig. 1).

When comparing Fig. 1 with Fig. 2 it is also possible to verify that seepage locations are respected in the numerical simulate models. It is worth mentioning the fact that the tailings started to be deposited directly on the ground without any previous preparation or drainage work. It is therefore expectable that these old streams exist and act as preferential conducts for groundwater circulation beneath the dam, being possibly responsible for the main hydrochemical exchanges due to hydrodynamic effects. The location of outflow derived from these old sreams coincides with the main seepage areas (Fig. 1). The numerical simulation 
results demonstrate the existence of a main flow with direction from SW to NE and another smaller flow with NW to SE direction. These flows remained even after the dam was requalified and are consistent with the old streams that existed previously to the tailings deposition. Their existence and remaining presence is related with the fact that they are established in the underling granite. Probably, the water lux comes through the area of the dam laterally, and depth wise, through local faults and high-density fracture areas.

According to numerical results and historical data of piezometric heads, two potentiometric surfaces were detected (Fig. 2). One is located within the tailings deposit and is associated with an expectable low permeability and difficult fluid percolation because of the high variability of the tailings materials while having a predominant silty and clayed nature with gravity compaction effects over the decades. In this case, the transmissivity of the flow is hampered, providing conditions to the storage of contaminated acidic waters within the deposit that circulate at a very low velocity rate which, in turn, make leakage and seepage more difficult. Hydrogeological behaviour of the tailings deposit after environmental remediation works is close to an aquitard and/or aquiclude. The other potentiometric surface is associated with the granitic rock massive. It has a very distinct hydraulic behaviour, as it is an unconfined aquifer that, when it crosses and underlies the tailings dam, it becomes a semi-confined to a confined aquifer. The more superficial area of the granite is considerably weathered and fractured and will act as a layer where the water percolation and flow is more facilitated.

These flow path results, as discussed and presented in Fig. 2, were subsequently considered for map overlapping with results derived from hydrochemical multivariate interpretations.

\subsection{PCA and K-Means cluster analysis}

The developed PCA analysis has reduced the data set from seven quantitative variables to three new variables, the principal components PC1, PC2 and PC3. This principal components explains $72,16 \%$ of the total variance (Table 1) which is a reasonable result considering the high variability of to hydrochemical data set. According to the results in Table 1, it is obvious the closer relation between the parameters SO4, $\mathrm{Cl}$ and $\mathrm{Mn}$, and, at a second correlation level, with Utotal and $\mathrm{Ca}$. $\mathrm{pH}$ has an inverse correlation for all these mentioned parameters. This is because, in acidic environments, as the $\mathrm{pH}$ increases to a value of $6-7$, the environmental conditions turns less acidic and the concentrations of contaminants drops. The hydrochemical profile of the contaminated waters generated in the tailings deposit is of acidic nature (low $\mathrm{pH}$ ) and has a high level of contamination in some characteristic anions, cations, base and semi-metals, including, in this particular case, Utotal and Ra226 because of the nature of the exploited ore in the past. One aspect of relevance is that, according to the PCA1 scores, Ra226 does not have the same behaviour profile of the others indicators Utotal, $\mathrm{SO} 4, \mathrm{Mn}, \mathrm{Cl}$ and $\mathrm{Ca}$. Its behaviour is better explained by the variables PCA2 and PCA3 from which it is possible to conclude that Ra226 will have some direct correlation with $\mathrm{pH}$, that is, as pH increases, Ra226 will have some tendency to increase as well. A subsequent KMC analysis was developed for all the qualitative samples $1 T 1,1 T 2,2 T 1,2 T 2,2 T 3,3 T 1,3 T 2,3 T 3,5 T 1,5 T 2,5 T 3,6 T 1$, $6 \mathrm{~T} 2,6 \mathrm{~T} 3,7 \mathrm{~T} 2,7 \mathrm{~T} 3,9 \mathrm{~T} 1,9 \mathrm{~T} 2,9 \mathrm{~T} 3,10 \mathrm{~T} 1,10 \mathrm{~T} 3,11 \mathrm{~T} 1,11 \mathrm{~T} 2$ and $11 \mathrm{~T} 3$ according with its scores in PCA1, PCA2 and PCA3. Tests with 4, 5 and 6 clusters were performed allowing the conclusion that better results were achieved for the case considering 6 clusters. For computing cluster analysis, the "maximum interaction number" was 100, the "n start number" was 25 and "Hartigan-Wong" was the algorithm 
considered. Representativeness of the results (between SS / total SS) was 90,1\%. Clustering vectors for all the samples were selected for interpretation, allowing the association of each one of the 6 clusters to its respective group of qualitative samples. That is, all qualitative samples were classified in one of the 6 clusters. The results of KMC are presented in Table 2. As expected, KMC results confirm the distinct hydrochemical profiles that are a result of the PCA analysis (Fig. 3). Each cluster represents a certain hydrochemical profile which, in turn, corresponds to the considered qualitative variables (of location and time stage). Each profile corresponds to certain specific contamination condition. From the results and interpretations in Table 2 is possible to verify the existence of a trend from cluster 1 to cluster 6 , from the most contaminated locations, in cluster 1 , to the less ones, in clusters 5 and 6 . Following this sequence, is possible to identify the locations within the tailings dam with positive evolutions in the consequence of environmental remediation works - piezometers $1,3,5,6$ and $11-$, and those who have a low but also positive evolution or which have stabilized in time - piezometers 2, 9, 10 and 11. 
Table 1

Scores, eigenvalues, and cumulative variances for variables PC 1, 2 , and 3.

\begin{tabular}{|c|c|c|c|}
\hline Variables & PC1 (Dim.1) & PC2 (Dim.2) & PC3 (Dim.3) \\
\hline \multicolumn{4}{|c|}{ Quantitative } \\
\hline SO4 & 0.81 & 0.14 & 0.08 \\
\hline $\mathrm{Cl}$ & 0.78 & 0.03 & 0.35 \\
\hline $\mathrm{Mn}$ & 0.78 & -0.07 & 0.35 \\
\hline Utotal & 0.68 & 0.36 & 0.05 \\
\hline $\mathrm{Ca}$ & 0.55 & -0.56 & -0.35 \\
\hline $\mathrm{Ra} 226$ & 0.34 & 0.66 & -0.58 \\
\hline $\mathrm{pH}$ & -0.59 & 0.41 & 0.42 \\
\hline \multicolumn{4}{|c|}{ Qualitative } \\
\hline $5 \mathrm{TT}$ & 3.64 & 2.13 & -0.51 \\
\hline 7T3 & 3.02 & -0.99 & 1.01 \\
\hline 7T2 & 2.62 & 0.43 & 0.76 \\
\hline $5 \mathrm{~T} 2$ & 2.38 & -0.76 & 0.37 \\
\hline $6 \mathrm{TT} 1$ & 1.75 & 0.41 & -0.51 \\
\hline $5 T 3$ & 0.98 & -0.72 & 0.73 \\
\hline $2 \mathrm{~T} 2$ & 0.89 & -0.79 & 0.37 \\
\hline $2 \mathrm{~T} 1$ & 0.49 & -0.42 & -0.29 \\
\hline $3 \mathrm{~T} 1$ & 0.36 & -0.65 & -0.35 \\
\hline $6 \mathrm{~T} 2$ & 0.34 & 2.19 & -3.39 \\
\hline $1 \mathrm{~T} 1$ & 0.17 & -0.60 & 0.12 \\
\hline $3 \mathrm{~T} 2$ & -0.11 & 0.46 & -1.30 \\
\hline 7T1 & -0.12 & -1.11 & -0.52 \\
\hline $6 \mathrm{~T} 3$ & -0.14 & -0.73 & 0.50 \\
\hline $9 \mathrm{~T} 2$ & -0.15 & 0.04 & -0.78 \\
\hline $2 T 3$ & -0.23 & -1.14 & -0.23 \\
\hline $11 \mathrm{~T} 1$ & -0.29 & -0.58 & 0.50 \\
\hline 9Т3 & -1.00 & -0.54 & -0.47 \\
\hline
\end{tabular}




\begin{tabular}{|llll|}
\hline Variables & PC1 (Dim.1) & PC2 (Dim.2) & PC3 (Dim.3) \\
\hline 1T2 & -1.12 & 0.55 & -0.75 \\
\hline 11T3 & -1.48 & 0.29 & -0.40 \\
\hline 10T1 & -1.48 & -0.16 & -0.06 \\
\hline 9T1 & -1.49 & -0.11 & -0.01 \\
\hline 3T3 & -1.56 & -0.12 & 0.09 \\
\hline 11T2 & -1.60 & 0.19 & 0.03 \\
\hline 10T3 & -1.80 & 0.56 & 0.05 \\
\hline 10T2 & -2.47 & 1.26 & 1.40 \\
\hline Eigenvalue & 3.09 & 1.07 & 0.89 \\
\hline Variance (\%) & $44.15 \%$ & $15.25 \%$ & $12.76 \%$ \\
\hline Variance (Cumul. \%) & $44.15 \%$ & $59.40 \%$ & $72.16 \%$ \\
\hline
\end{tabular}


Table 2

Results of KMC. Hadrochemical profiles with its respective classification and interpretation for each cluster is presented.

\begin{tabular}{|c|c|c|c|c|c|c|c|c|c|}
\hline Cluster/ & $\begin{array}{l}\text { Univariate } \\
\text { Statistics }\end{array}$ & $\mathrm{pH}$ & $\mathrm{U}_{\text {tot }}$ & $\begin{array}{l}\text { Ra- } \\
226\end{array}$ & Mn & so4 & $\mathrm{Cl}$ & $\mathrm{Ca}$ & Interpretation \\
\hline Piezometer/ & & & & & & & & & $\begin{array}{l}\text { Specific site } \\
\text { environment }\end{array}$ \\
\hline $\begin{array}{l}\text { Time } \\
\text { interval }\end{array}$ & & & & & & & & & conditions \\
\hline
\end{tabular}

\begin{tabular}{lllllllll}
1 & Mean & 3,2 & 23667 & 1447 & 438 & 11163 & 657 & 331 \\
5T1 & & & & & & & & \\
& & & & & & & & \\
\cline { 2 - 8 } & St. Dev. & 0,1 & 1528 & 90 & 126 & 8613 & 34 & 123
\end{tabular}

Very

contaminated

acid

environment.

All parameters have high concentrations.

$\begin{array}{llllllll}\text { Minimum } & 3,1 & 22000 & 1390 & 309 & 1490 & 630 & 190\end{array}$

$\mathrm{U}_{\text {tot, }}$ Ra-226

and SO4 with extremely high to very high concentrations $\begin{array}{lllllllll}\text { Maximum } & 3,3 & 25000 & 1550 & 560 & 18000 \quad 695 & 415 & \begin{array}{l}\text { while Cl, Mn } \\ \text { and Ca have }\end{array}\end{array}$ high concentrations.

$\begin{array}{llllllllll}2 & \text { Mean } & 3,2 & 5603 & 622 & 534 & 8483 & 893 & 395 & \begin{array}{l}\text { Very } \\ \text { contaminated }\end{array}\end{array}$

$\begin{array}{llllllll}\text { St. Dev. } \quad 0,2 & 4906 & 762 & 347 & 6071 & 411 & 219\end{array}$

$\begin{array}{lllllllll}\text { 7T2, 7T3, } & \text { Minimum } & 2,9 & 10 & 1 & 41 & 1400 & 391 & 136\end{array}$ $5 \mathrm{~T} 2,6 \mathrm{~T} 1$

$\begin{array}{llllllll}\text { Minimum } & 2,9 & 10 & 1 & 41 & 1400 & 391 & 136 \\ & & & & & & & \\ \text { Maximum } & 3,6 & 13709 & 2000 & 994 & 19647 & 1527 & 914\end{array}$

acid

environment.

Similar to Cluster 1 but concentrations of $U_{\text {tot }}$, Ra-226 and SO4 tend to be lower.

\begin{tabular}{|c|c|c|c|c|c|c|c|c|c|}
\hline \multirow{3}{*}{$\begin{array}{l}3 \\
6 \mathrm{~T} 2\end{array}$} & Mean & 5,4 & 697 & 3200 & 150 & 2200 & 38 & 470 & \multirow{3}{*}{$\begin{array}{l}\text { Environment } \\
\text { with some } \\
\text { specific } \\
\text { contaminants. } \\
\text { pH slightly } \\
\text { acidic; Ra-226 } \\
\text { with very high } \\
\text { concentrations }\end{array}$} \\
\hline & St. Dev. & - & - & - & - & - & - & - & \\
\hline & Minimum & - & - & - & - & - & - & - & \\
\hline
\end{tabular}




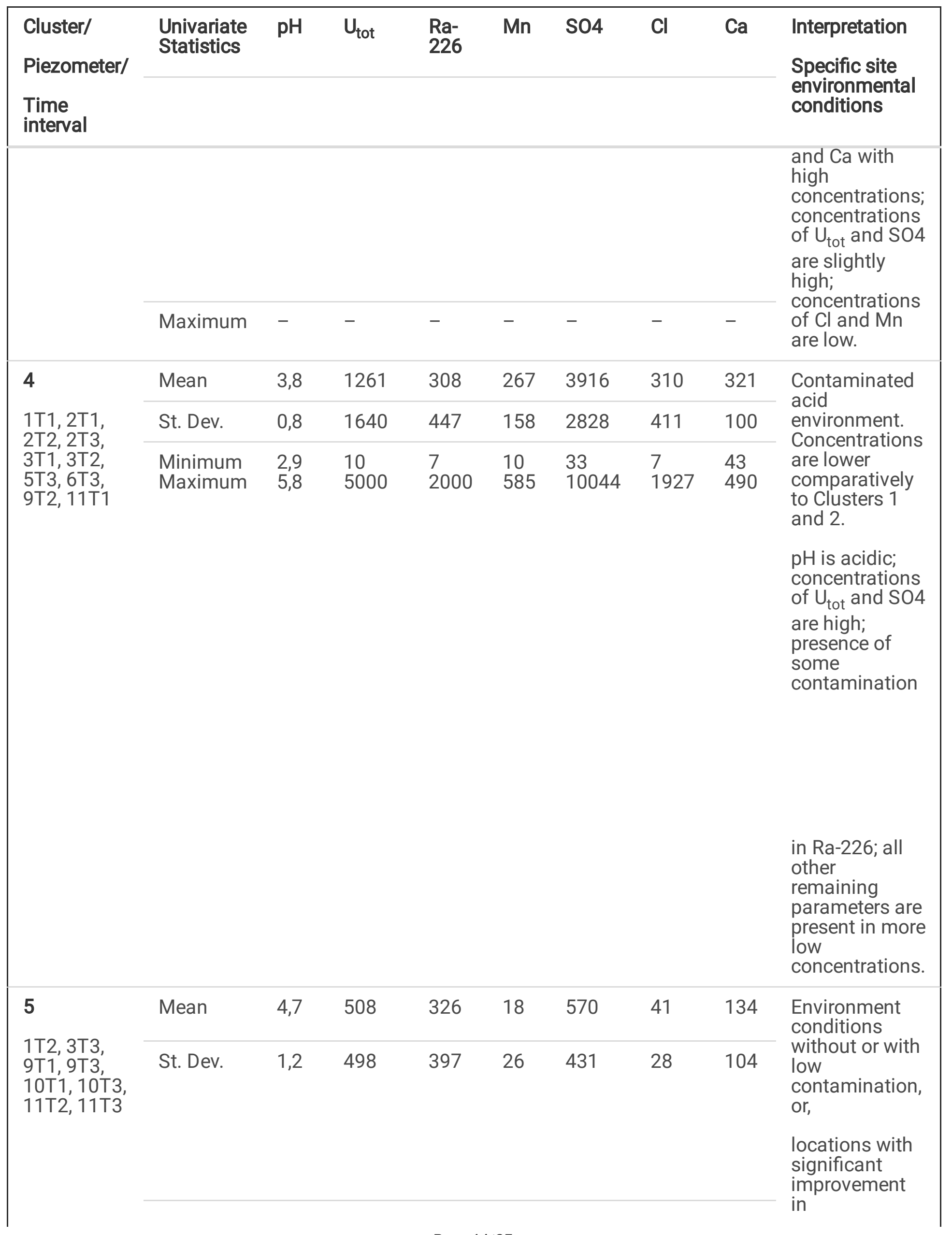




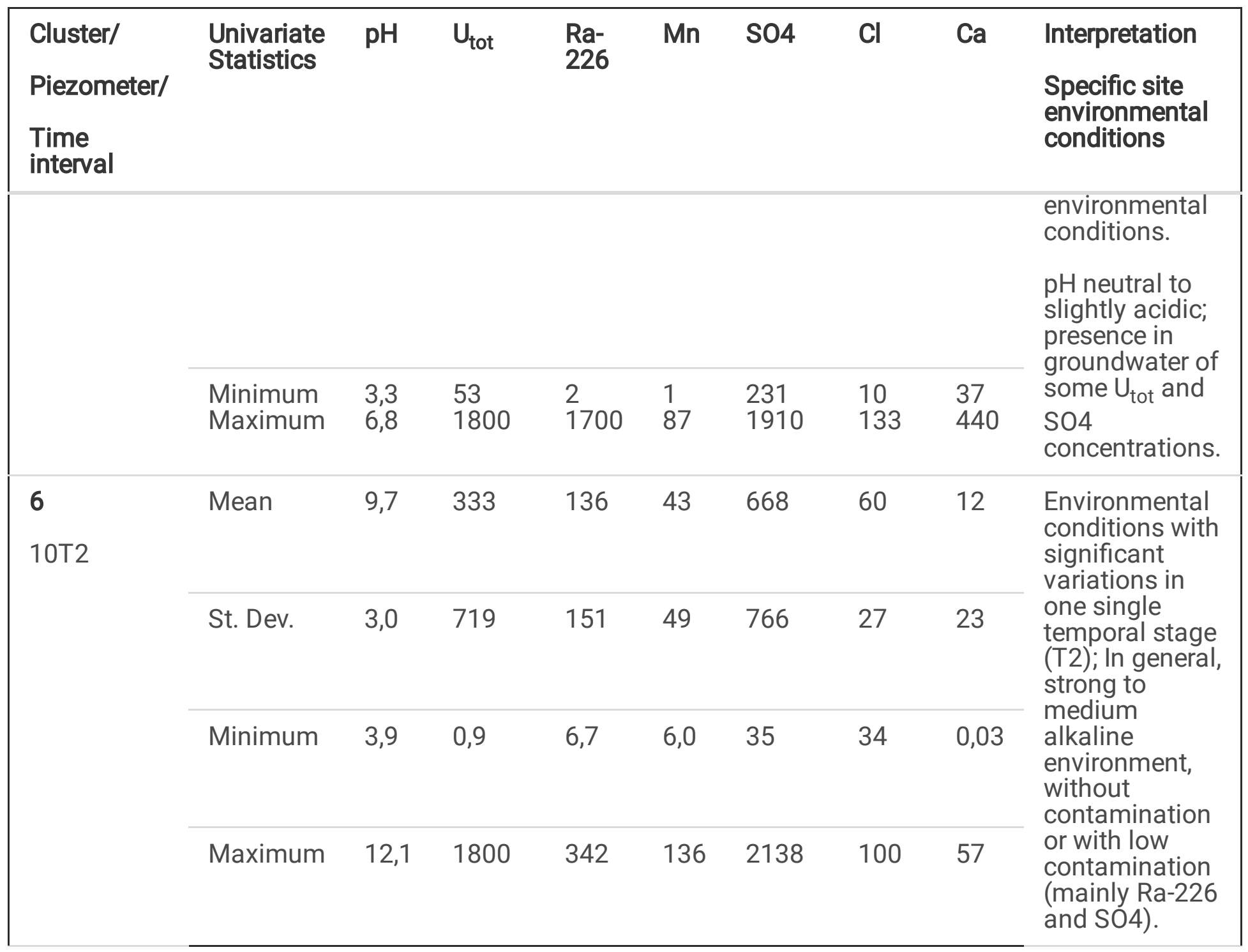

Afterwards, the first three PC scores (PC1, PC2 and PC3) for all sample locations and time intervals, 1T1, 1T2, 2T1, 2T2, 2T3, 3T1, 3T2, 3Т3, 5T1, 5T2, 5T3, 6T1, 6T2, 6T3, 7T2, 7T3, 9T1, 9T2, 9T3, 10T1, 10T3, 11T1, $11 \mathrm{~T} 2$ and $11 \mathrm{~T} 3$ were mapped at 2D, in the area of the tailings dam, through its spatial interpolation with kriging. The interpretative maps of PCA and KMC results for the case of PCA1 variable at each time interval $\mathrm{T} 1, \mathrm{~T} 2$ and T3 are presented in Fig. 4. From this figure and considering previous results presented in Tables 1 and 2 , it is possible to consider the following conclusions:

PCA1-T1: a) Cluster 1 represents the most contaminated hydrochemical profile and is associated to variable $5 \mathrm{~T} 1$ (that is, to the location of piezometer 5 at the pre-remediation stage). The profile with the highest contamination detected in the monitoring plan is only present at time period T1 (that is, before the environmental remediation). It represents an acid environment with all parameters having high to very high concentrations. Utotal, Ra226 and SO4 have extremely high to very high concentrations. $\mathrm{Cl}, \mathrm{Mn}, \mathrm{Ca}$ have high concentrations. b) At this same time period (T1), piezometer 6 is the other one that also has a much demarcated contamination pattern and it is represented by cluster 2 . This cluster also represents a profile of an acidic environment, similar to the environment of cluster 1 but with lower Ra266 concentrations. c) In the 
remaining area of the tailings dam the profiles are of type C4 and C5. Environmental conditions are better with less effects of contamination, groundwater is less contaminated (cluster 4) or only slightly contaminated or not contaminated (cluster 5).

PCA1-T2 and PCA1-T3: at T2 the profile of piezometer 5 is represented by cluster 2. During the remediation works, piezometer 5 evolved to a less extremely high contaminated profile although it still remains with high contamination. It is also possible to conclude that this contamination profile spreads upward from piezometer 5 to piezometer 7 . These evolutions during period T2 are spatially close to the location of the main old stream water underneath the tailings with main direction from SW to NE which which is highlighted from numerical groundwater modelling. It seems that, somehow, and probably in the dependence of local hydrodynamic flow, the main contamination plume has migrated Northwards from site 5 to site 7. Another interesting hydrochemical behaviour is detected in the area of piezometer 6 which has, in the period T2, a hydrochemical profile represented by cluster 3 . In this case, local environmental conditions are less acidic to more close to neutral. All the concentrations decrease with the exception of Ra226, SO4 and Ca. This behaviour is reported by PCA2 scores and is well reflected in map PCA2-T2 (Fig. 5) however; it is not well represented statistically (Table 2, cluster $3, n=1$ ) despite conditioning the analysis. Also locally, at piezometer 10 , during the period T2, an alkaline profile is detected. This fact is probably related with some earth movements in the Northern part of the tailings dam, during remediation works for the re-profiling of slopes, where old tailings materials were either moved or rotated, inducing influence on the materials which have a more carbonated composition. Here, the alkaline or close to neutral waters and the presence of some ions in freshwaters that inflow through the northwest part of the dam, like chloride (and sulphate), may have also helped facilitate the temporary remobilization and transportation of Ra226. This possible phenomena may be observed in Fig. 5. In T2 and T3 periods, all the other sites at the tailings dam present profiles of very less contamination (cluster 4) or of environmental conditions without or with very low contamination (cluster 5). In periods T2 and T3, slightly contaminated profiles maybe present in some locations that are represented by cluster 4 . This behaviour may be related with mixing groundwater effects from fresh waters that inflow laterally at western and northwestern and from SW to NE direction, which results in $\mathrm{pH}$ increments and general reduction in hydrochemical concentrations. After the remediation works, that is, in T3 period, contamination is much more circumscribed and only remains in the location of piezometer 7 (PCA1-T3 map). In T3 the only location with remaining strong contamination is given by piezometer 7 . All the other studied sites present a significant improvement regarding groundwater quality.

\subsection{Interpretation map of groundwater evolution and oxidizing frontier}

Superposition of numerical groundwater models with the maps of multivariate analysis made possible the interpretation of water quality evolution in the tailings dam area and in time (Fig. 6). Two main inflow paths were detected in the area beneath the tailings dam: E3, with its direction from SW to NE, and E1 that inflows at Northwest side with preferential circulation from NW to SE. E1 is more related with good water quality profiles while E3 has probably the influence of leakage and seepage from the tailings deposit due to the temporary expansion of contamination registered in the period T2, immediately after the environmental remediation works. 
The interpretative maps obtained (Fig. 6) evidence the existence of an oxidation front, with washing and dilution effects, that is related with the individualization of two main areas: one, more centrally located and with influence on the Eastern seepage, where a plume with strong contamination probably have migrated to the North according to the E3 flow direction, and, another area, in the North, directly influenced by E1 inflow, with very low contamination to non-contaminated hydrochemical profiles. In this area, the less thickness of the tailings deposit associated with the refreshing of groundwater from inflow of E3 (and E2) will have an important role on the improvement of groundwater quality that was detected. Seepage from the tailings deposits will be of very low velocities, especially after remediation works, once the area of the dam is covered by a multi-layer system with impermeable layers. This fact is also related with the reduction of the area of stronger contamination and general improvement of groundwater quality.

The maintenance of inflow after environmental remediation works is related with the old stream line that underlays the tailings deposit and probably faults and high intensity fracture zones in the granite, which promote percolation underneath the deposits area. It seems that the migration of the contamination plume is controlled by this phenomenon and will be more restricted to the superficial area of the granite that presents higher weathering effects and/or higher fracture densities. Migration of contamination in depth, in the granite, will be more restricted and related to relevant faults and high density, and interconnectivity of productive fractures.

\section{Conclusions}

The integration of PCA scores in a KMC analysis facilitates multivariate interpretations of PCA results, allowing a better clarification of the sense of PCA grouping relations through the clusters that are obtained. In our study, mapping of PCA scores and its interpretation with KMC allowed a better understanding of spatio-temporal trends within the tailings dam. Superposition of these results with the main stream line of flow obtained from groundwater models allow a more comprehensive interpretation of the water quality evolution in time considering simultaneously all the hydrochemical indicators. KMC results of PCA scores facilitated interpretations and temporal and spatial analysis. Spatial mapping of KMC and PCA scores allows a more synthetic, faster and easier approach when multivariate indicators need to be considered for an evaluation of contamination profiles. In this case study, clusters of KMC represent distinct groundwater quality hydrochemical profiles. Evolution of environmental conditions at each site location (that is, at each piezometer) in accordance with the identified groundwater quality profiles was performed. KMC enabled a better understanding of the PCA results once observations were classified according to distinct hydrochemical profiles at each piezometer location, according to each time-period T1, T2 and T3. Subsequently, distinct areas within the dam were demarcated according to different degrees of contamination and non-contamination profiles.

Superposition of numerical groundwater models with multivariate analysis allowed the identification of main potential flow paths that are related with hydrochemical evolutions and plume contamination migration. 
The concentrations of total uranium, sulphate, chloride, manganese and calcium decrease in consequence of $\mathrm{pH}$ increment. In turn, and temporarily, at an intermediate stage, radium-226 concentrations increased in some circumscribed locations, probably in consequence of $\mathrm{pH}$ increase, of more oxidizing environment conditions and mixing phenomena with fresh waters derived from preferential inflow path. In the postremediation period, a general improvement in groundwater quality is verified.

Effects of an oxidizing frontier that develops within the tailings dam were detected. This oxidizing frontier (more correctly, oxidizing-reduction frontier) evolved during the periods of time T1, T2 and T3 and is a consequence of an inflow and flow streams underneath the tailings dam. There is sufficient evidence of the improvement on groundwater quality in the consequence of the environmental remediation works developed.

\section{Declarations}

\section{Funding}

This work is a contribution to Project UIDB/04035/2020 funded by FCT-Fundação para a Ciência e a Tecnologia, Portugal.

\section{Conflicts of interest/Competing interests}

Not applicable.

\section{Availability of data and material}

All data and models used and generated during the study are proprietary and confidential in nature and may only be provided with restrictions (e.g. anonymized data) (data of hydrochemical indicators was provided by EDM, S.A; the generated numerical models were developed on a Geological Engineering Master Thesis with public restriction conditions being referred as Pinto M. (2016)).

\section{Code availability}

All modelling and data processing software used are freeware or open source.

\section{Authors' Contributions}

MP and SB conceived and planned the work, interpreted the results and wrote the manuscript. JA, EC and CD provided critical feedback, helped the data compilation and research and the manuscript review.

\section{References}

ASTM D2487-11 Directive: Standard Practice for Classification of Soils for Engineering Purposes (Unified Soil Classification System, USCS). 
ATSDR (Agency for Toxic Substances and Disease Regestry), 2011. Toxicological Profile for Uranium, in Toxic Substances Portal, Agency for Toxic Substances and Disease Registry, 339-357.

https://www.atsdr.cdc.gov/toxprofiles/tp150-c7.pdf, Accessed 20 November 2017.

Anghileri, D., Pianosi, F., \& Soncini-Sessa, R. (2014). Trend detection in seasonal data: from hydrology to water resources. Journal of Hydrology, 511, 171-179. ISSN 0022-1694,

https://doi.org/10.1016/j.jhydrol.2014.01.022.

Berkowitz, B., Bear, J., Braester, C. (1998). Continuum models for contaminant transport in fractured porous formations. Water Resources Research, 24, 8, 1225-1236. https://doi.org/10.1029/WR024i008p01225

Blessent, D., Jørgensen, P. R., Therrien, R. (2014). Comparing Discrete Fracture and Continuum Models to Predict Contaminant Transport in Fractured Porous Media. Groundwater, 52 (1), 84-95.

Boyacioglu, H., \& Boyacioglu, H. (2008). Investigation of Temporal Trends in Hydrochemical Quality of Surface Water in Western Turkey. Bull Environ Contam Toxicol, 80, 469-474. https:doi.org/10.1007/s00128008-9439-0

Chandler, R. E., Scott, E. M. (eds.). (2011). Statistical Methods for Trend Detection and Analysis in the Environmental Sciences. John Wiley \& Sons, Ltd. https:doi.org/10.1002/9781119991571.

Chen, S., He, Q., Cao, J. (2018). Seepage simulation of high concrete-faced rockfill dams based on generalized equivalent continuum model. Water Science and Engineering, 11, 3, 250-257. ISSN 1674-2370. https://doi.org/10.1016/j.wse.2018.10.004.

Chiang, W. H., Kinzelbach, W. (1998). PMWIN, Processing Modflow, A Simulation System for Modeling Groundwater Flow and Pollution. Hamburg, Zürich, 334 p.

Chiang, W. H., Kinzelbach, W. (2001). 3D-Groundwater Modeling with PMWIN, First Edition. Springer Berlin Heidelberg New Yourk, 346 p. ISBN 3-540-67744-5.

Cooper, R. J. , Hiscock, K. M. , Lovett, A. A. , Dugdale, S. J., Sünnenberg, G., Vrain, E. (2020).

Temporal hydrochemical dynamics of the River Wensum, UK: Observations from long-term high-resolution monitoring (2011-2018), Science of The Total Environment, 724, 138253. ISSN 0048-9697, https://doi.org/10.1016/j.scitotenv.2020.138253.

Diamantino, C., Carvalho, E., Pinto, R. (2016). Water resources monitoring and mine water control in Portuguese old uranium mines. Proceeding of IMWA2016 Annual Conference, July 11-15, Leipzig, Germany.

Ding, C., He, X. (2004). Cluster Structure of K-means Clustering via Principal Component Analysis. In: Dai H., Srikant R., Zhang C. (eds) Advances in Knowledge Discovery and Data Mining. PAKDD 2004. Lecture Notes in Computer Science, vol 3056. Springer, Berlin, Heidelberg. https://doi.org/10.1007/978-3-540-24775-3_50. 
Durlofsky, L. J. (1991). Numerical calculation of equivalent grid block permeability tensors for heterogeneous porous media. Water Resour. Res., 27-5, 699-708ttps://doi.org/10.1029/91WR00107.

EDM. (2011). The legacy of abandoned mines - The context and the action in Portugal. EDM and DGEG (eds.). http://ec.europa.eu/environment/waste/mining/pdf/Appendix_II_to_Annex3.pdf.

Helena, B., Pardo, R., Veja, M., Barrado, E., Fernandez, J. M., Fernandez, L. (2000). Temporal evolution of groundwater composition in an alluvial aquifer (Pisuerga River, Spain) by principal component analysis. Water Research, Vol. 34, Issue 3, 807-816. https://doi.org/10.1016/S0043-1354(99)00225-0

Hirsch, R. M., Slack, J. R., Smith, R. A. (1982). Techniques of trend analysis for monthly water quality data. Water Resour. Res., 18-1, 107-121. https://doi.org/10.1029/2009WR008071.

Hirsch, R.M., Slack, J.R. (1984). A Nonparametric Trend Test for Seasonal Data with Serial Dependence. Water Resources Research, 20, 727-732. https://doi.org/10.1029/WR020i006p00727.

Hothorn, T., Everitt, B. S. (2005). A Handbook of Statistical Analyses using R. CRAN.R-project.org document. https://cran.r-project.org/web/packages/HSAUR3. Accessed 15 January 2017.

Hothorn, T., Everitt, B. S. (2017). A Handbook of Statistical Analyses using R. Chapman \& Hall/CRC Press, Third Edition.

Howard, A. K. (1986). Soil Classification Handbook: Unified Soil Classification System. Denver, Colorado: Geotechnical Branch, Division of Research and Laboratory Services, Engineering and Research Center, Bureau of Reclamation.

ISRM, International Society for Rock Mechanics (1981). Rock Characterization, Testing and Monitoring ISRM Suggested Methods, Pergamon Press, Oxford, UK.

Jeong, J. T., Lee, K. J. (1999). A single continuum approximation of the solute transport in fractured porous media. Annals of Nuclear Energy, 19, 8, 459-470.

Keith, L.S., Faroon, O. M., Fowler, B. A. (2014). Uranium. In G. F. Nordberg, B. A. Fowler, M. Nordberg (eds.), Handbook on the Toxicology of Metals (pp. 881-900). Academic Press, Fourth Edition.

Kim, D., Kim, Se-K. (2012). Comparing patterns of component loadings: Principal Component Analysis (PCA) versus Independent Component Analysis (ICA) in analysing multivariate non-normal data. Behav. Res. (2012), 44:1239-1243. https://doi.org/10.3758/s13428-012-0193-1.

Khoei, A.R., Hosseini, N., Mohammadnejad, T. (2016). Numerical modeling of two-phase fluid flow in deformable fractured porous media using the extended finite element method and an equivalent continuum model. Advances in Water Resources, 94, 510-528.

Koonce, J.E., Yu, Z., Farnham, I.M., Stetzenbach, K.J. (2006). Geochemical interpretation of groundwater flow in the southern Great Basin. Geosphere, 2 (2), 88-101. https://doi.org/10.1130/GES00031.1 
Kundzewicz, Z.W., Robson, A.J. (2004). Change Detection in Hydrological Records - A Review of the Methodology. Hydrological Sciences Journal, 49, 7-19.

$\mathrm{Li}, \mathrm{H} .$, \& Gao, Y. (2018). Multivariate statistical approaches to identify the major factors governing groundwater quality. Appl. Water Sci. 8, 215. https://doi.org/10.1007/s13201-018-0837-0

Le, S., Josse, J., Husson, F. (2008). FactoMineR: An R Package for Multivariate Analysis. Journal of Statistical Software, 25(1), 1-18. https://doi.org/10.18637/jss.v025.i01

Ledesma-Ruiz, R., Pastén-Zapata, E., Parra, R., Harter, T., Mahlknecht, J. (2015). Investigation of the geochemical evolution of groundwater under agricultural land: A case study in Northeastern Mexico. Journal of Hydrology, 521, 410-423.

Machiwala, D., \& Madan, K. J. (2015). Identifying sources of groundwater contamination in a hard-rock aquifer system using multivariate statistical analyses and GIS-based geostatistical modeling techniques. Journal of Hydrology: Regional Studies, 4, 80-110.

Mandel, P., Maurel, M., Chenu, D. (2015). Better understanding of water quality evolution in water distribution networks using data clustering. Water Research, 87, 69-78.

Marín Celestino, A.E., Ramos Leal, J.A., Martínez Cruz, D.A., Tuxpan Vargas, J., De Lara Bashulto, J., Morán Ramírez, J. (2019). Identification of the Hydrogeochemical Processes and Assessment of Groundwater Quality, Using Multivariate Statistical Approaches and Water Quality Index in a Wastewater Irrigated Region. Water, 11, 1702. https://doi.org/10.3390/w11081702

McDonald, M.G., \& Harbaugh, A.W. (1988) A Modular Three-Dimensional Finite-Difference Ground-Water Flow Model. Techniques of Water-Resources Investigations, 06-A1, $586 \mathrm{p}$.

Monteith, D.T., Evans, C.D., Henrys, P.A. , Simpson, G.L., Malcolm, I.A. (2014). Trends in the hydrochemistry of acid-sensitive surface waters in the UK 1988-2008. Ecological Indicators, 37, Part B, 287-303. ISSN 1470160X, https://doi.org/10.1016/j.ecolind.2012.08.013.

Mozejko, J. (2012). Detecting and Estimating Trends of Water Quality Parameters in Water Quality Monitoring and Assessment, Dr. Voudouris (Ed.). ISBN: 978-953-51-0486-5.

Samardzioska, T., \& Popov, V. (2005). Numerical comparison of the equivalent continuum, nonhomogeneous and dual porosity models for flow and transport in fractured porous media. Advances in Water Resources, 28, 3, 235-255.https://doi.org/10.1016/j.advwatres.2004.11.002.

Pearson, K. (1901). On lines and planes of closest fit to systems of points in space. Philosophical Magazine, 2:559-572. In <http://pbil.univ-lyon1.fr/R/pearson1901.pdf>

Peng, K., Li, X. \& Wang, Z. (2015). Hydrochemical characteristics of groundwater movement and evolution in the Xinli deposit of the Sanshandao gold mine using FCM and PCA methods. Environ. Earth Sci., 73,78737888. https://doi.org/10.1007/s12665-014-3938-6 
Pinto, M. (2016). Spatio-temporal evolution of hydrodynamic and hydrochemical conditions in a former tailings dam as a result of its environmental remediation (Evolução espácio-temporal das alterações hidrodinâmicas e hidroquímicas numa antiga barragem de rejeitados mineiros em resultado de obras de recuperação ambiental). MSc Dissertation, Faculty of Science and Technology, NOVA University of Lisbon.

R Core Team (2013). R: A language and environment for statistical computing. R Foundation for Statistical Computing, Vienna, Austria. http://www.R-project.org/.

Rahlf, T. (2017). Data Visualisation with R - 100 Examples. Springer. e-Book ISBN: 978-3-319-49751-8.

Samardzioska, T., Popov, V. (2005). Numerical comparison of the equivalent continuum, non-homogeneous and dual porosity models for flow and transport in fractured porous media. Advances in Water Resources, $28,235-255$.

Santos, J. F., Pulido-Calvo, I., \& Portela, M. M. (2010). Spatial and temporal variability of droughts in Portugal. Water Resour. Res., 46, W03503.https://doi.org/10.1029/2009WR008071

Scanlon, B. R., Mace, R. E., Barrett, M. E., Smith, B. (2003). Can we simulate regional groundwater flow in a karst system using equivalent porous media models? Case study, Barton Springs Edwards aquifer, USA. Journal of Hydrology, 276 (1-4), 137-158. https://doi.org/10.1016/S0022-1694(03)00064-7.

Selvakumar, S., Chandrasekar, N., Kumar, G. (2017). Hydrogeochemical characteristics and groundwater contamination in the rapid urban development areas of Coimbatore, India. Water Resources and Industry, $17,26-33$.

Sotomayor, G., Hampel, H., Vázquez, R. F. (2018). Water quality assessment with emphasis in parameter optimisation using pattern recognition methods and genetic algorithm. Water Research, 130, 353-362.

Swanson, S. K., Bahr, J. M., Schwar, M. T., Potter, K. W. (2001). Two-way cluster analysis of geochemical data to constrain spring source waters. Chemical Geology, 179, 73-91.

Templ, M., Filzmoser, P., Reimann, C. (2008). Cluster analysis applied to regional geochemical data: Problems and possibilities. Applied Geochemistry, 23, 2198-2213.

Thyne, G., Güler, C., Poeter, E. (2008). Sequential Analysis of Hydrochemical Data for Watershed Characterization. Ground Water, Vol. 42, 5, 711-723. https://doi.org/10.1111/j.1745-6584.2004.tb02725x

Voudouris, K., Panagopoulos, A. \& Koumantakis, J. (2000). Multivariate Statistical Analysis in the Assessment of Hydrochemistry of the Northern Korinthia Prefecture Alluvial Aquifer System (Peloponnese, Greece). Natural Resources Research, 9, 135-146. https://doi.org/10.1023/A:1010195410646

Wuttichaikitcharoen, P., Babel, M. S. (2014). Principal Component and Multiple Regression Analyses for the Estimation of Suspended Sediment Yield in Ungauged Basins of Northern Thailand. Water 2014, 6, 24122435; https://doi.org/10.3390/w6082412 
Yan, X., Huang, Z., Yao, J., Zhang, Z., Liu, P., Li, Y., Fan, D. (2019). Numerical simulation of hydro-mechanical coupling in fractured vuggy porous media using the equivalent continuum model and embedded discrete fracture model. Advances in Water Resources, 126, 137-154. ISSN 0309-1708.

https://doi.org/10.1016/j.advwatres.2019.02.013.

Yeung, K. Y., Haynor, D. R., Ruzzo, W. L. (2001). Validating clustering for gene expression data. Bioinformatics, Volume 17, Issue 4, 309-318.ttps://doi.org/10.1093/bioinformatics/17.4.309

Wahlin, K., \& Grimvall, A. (2008). Uncertainty in water quality data and its implications for trend detection: lessons from Swedish environmental data. Env. Science \& Policy, 11, 2, 115-124. ISSN 1462-9011, https://doi.org/10.1016/j.envsci.2007.12.001.

Zhang, B., Song, X., Zhang, Y., Han, D., Tang, C., Yu, Y., Ma, Y. (2012). Hydrochemical characteristics and water quality assessment of surface water and groundwater in Songnen plain, Northeast China, Water Resour. Res., 46, 2737-2748.

Zhang, Q., Wang, H., Wang, Y., Yang, M., Zhu, L. (2017). Groundwater quality assessment and pollution source apportionment in an intensely exploited region of northern China. Environ. Sci. Pollut. Res., 24, 16639-16650 (2017). https://doi.org/10.1007/s11356-017-9114-2.

\section{Figures}

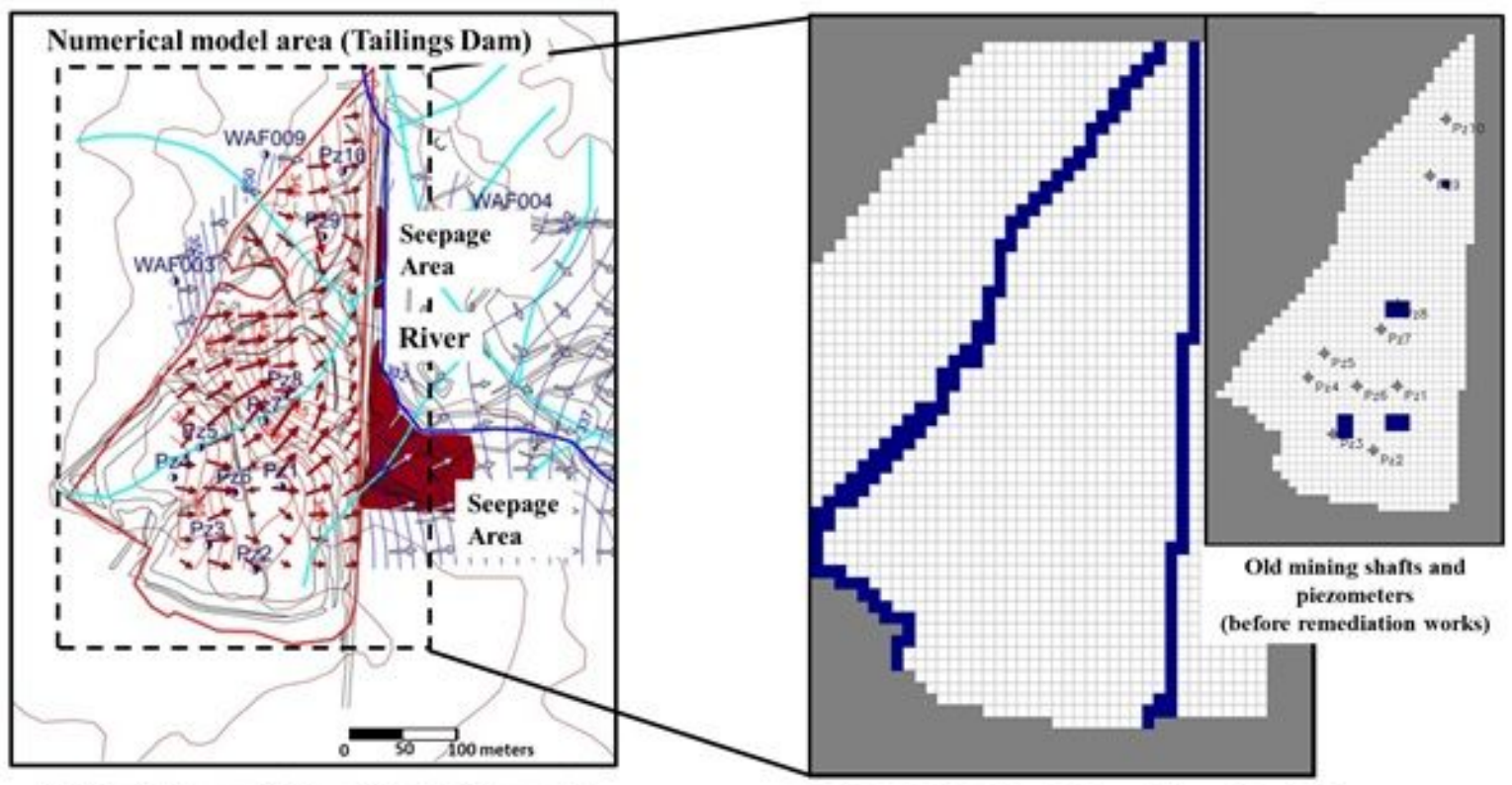

a) Map interpretation of main flow path Tailings dam on the left

b) Model Grid and Boundary Conditions

Figure 1

a) Conceptual model of water potential surface and flow path in the tailing dam and in the surrounding granite. Main seepage areas related with the location of old stream lines circulating beneath the tailings dam and in the surrounding granite are represented. The old streams and the actual location of the main 
river are also indicated (adapted from Pinto, 2016) b) Grid of the numerical models and boundary conditions. Location of old mining shaft and piezometers are also indicated (2D planar view, XY plan).

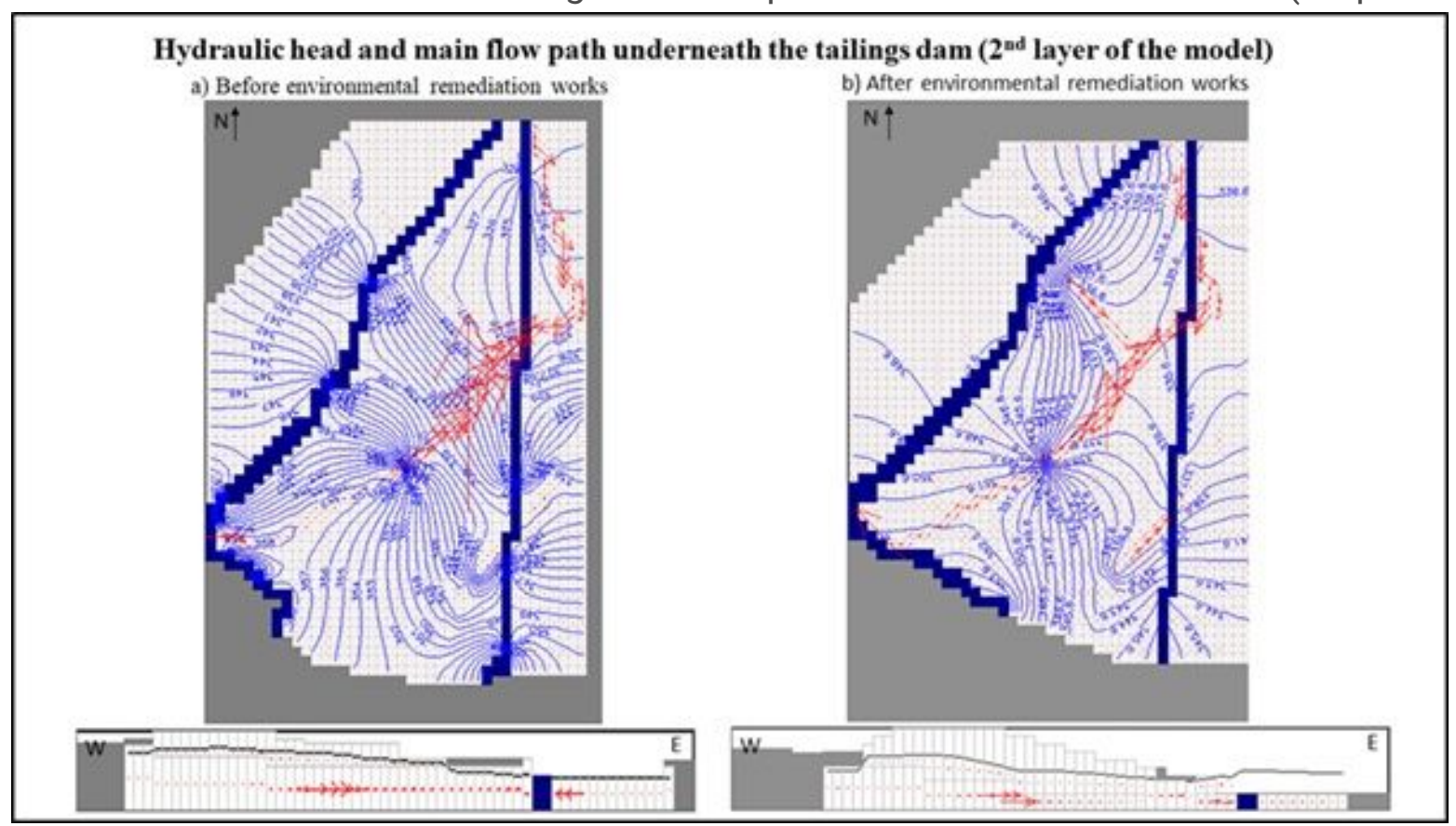

\section{Figure 2}

Results of the simulated numerical groundwater models for the cases of a) before and b) after the environmental remediation works. 2D planar $X Y$ and $Y Z$ (or W-E) sections are shown for the case of the second layer, that is, for the underlying granite (adapted from Pinto, 2016). 

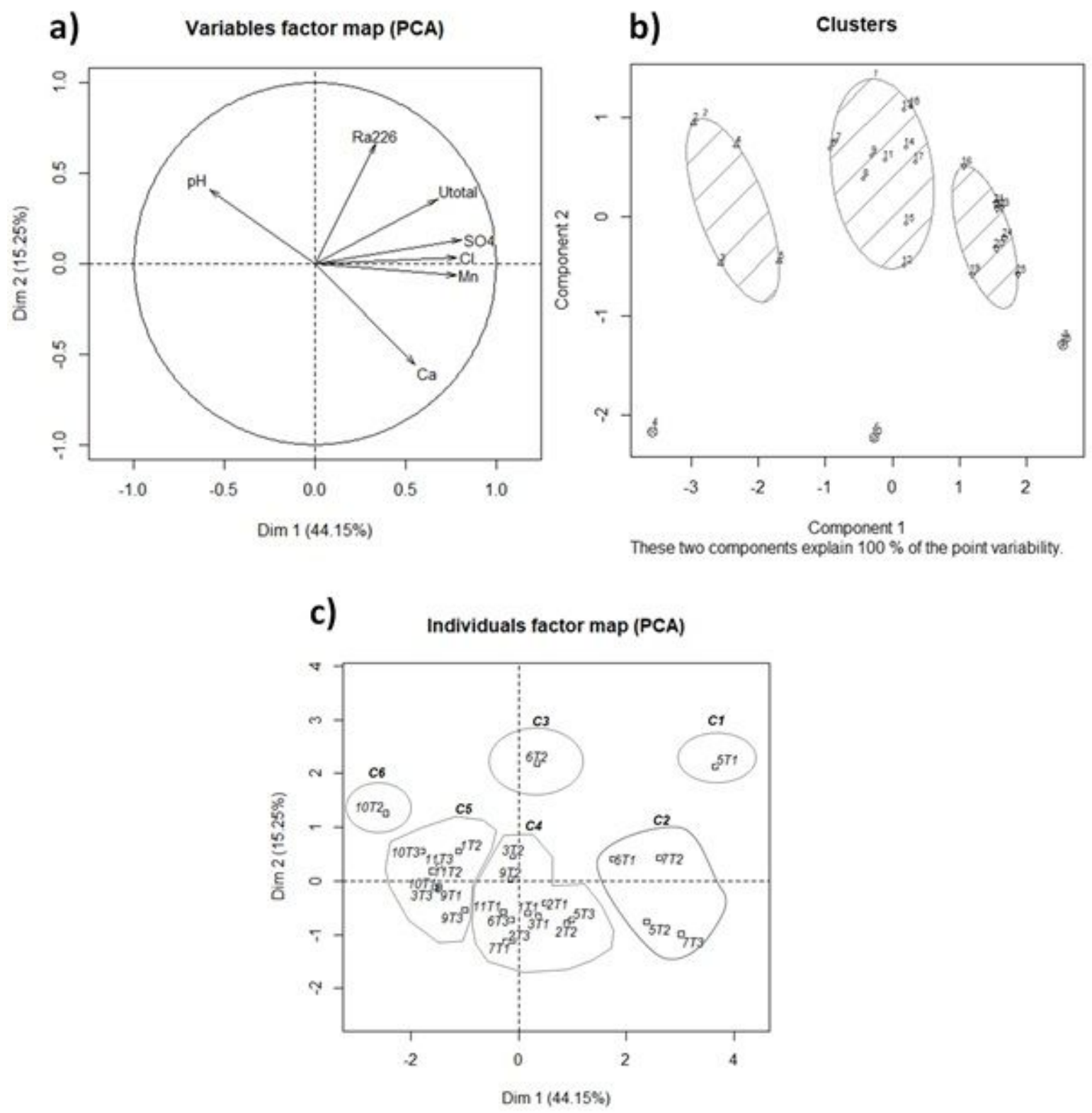

\section{Figure 3}

Interrelation between results of PCA and KMC a) Projection of quantitative variables in PCA1 and PCA2. b) $\mathrm{KMC}$ considering 6 clusters $\mathrm{c}$ ) Adequation of the clustering results to PCA results for the case of the qualitative variables. 

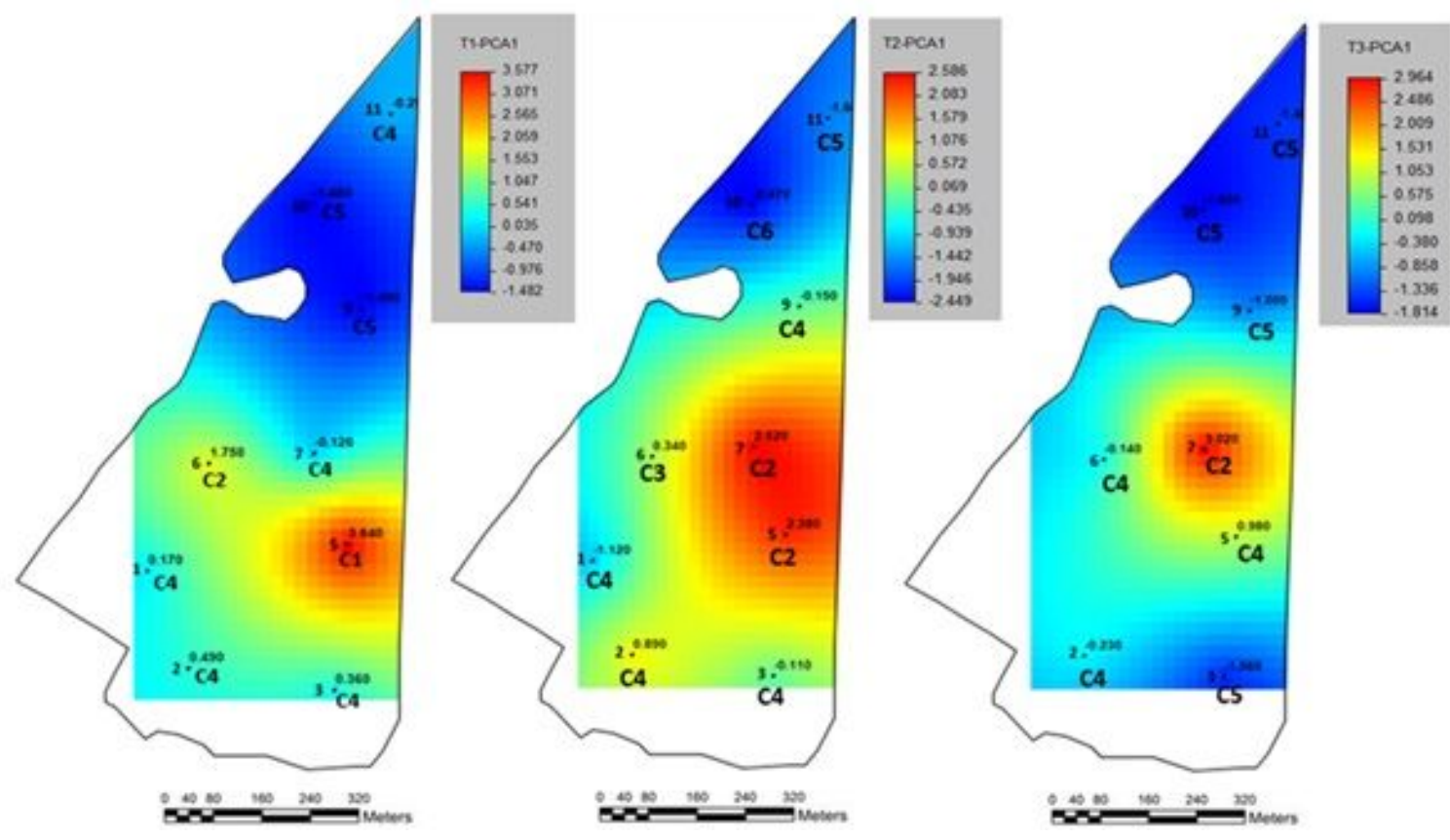

Figure 4

Mapping of PCA1 scores for time periods $\mathrm{T} 1, \mathrm{~T} 2$ and $\mathrm{T} 3$. For a better spatial interpretation, $\mathrm{KMC}$ results (clusters $\mathrm{c} 1$ to $\mathrm{c} 6$ ) are also represented.
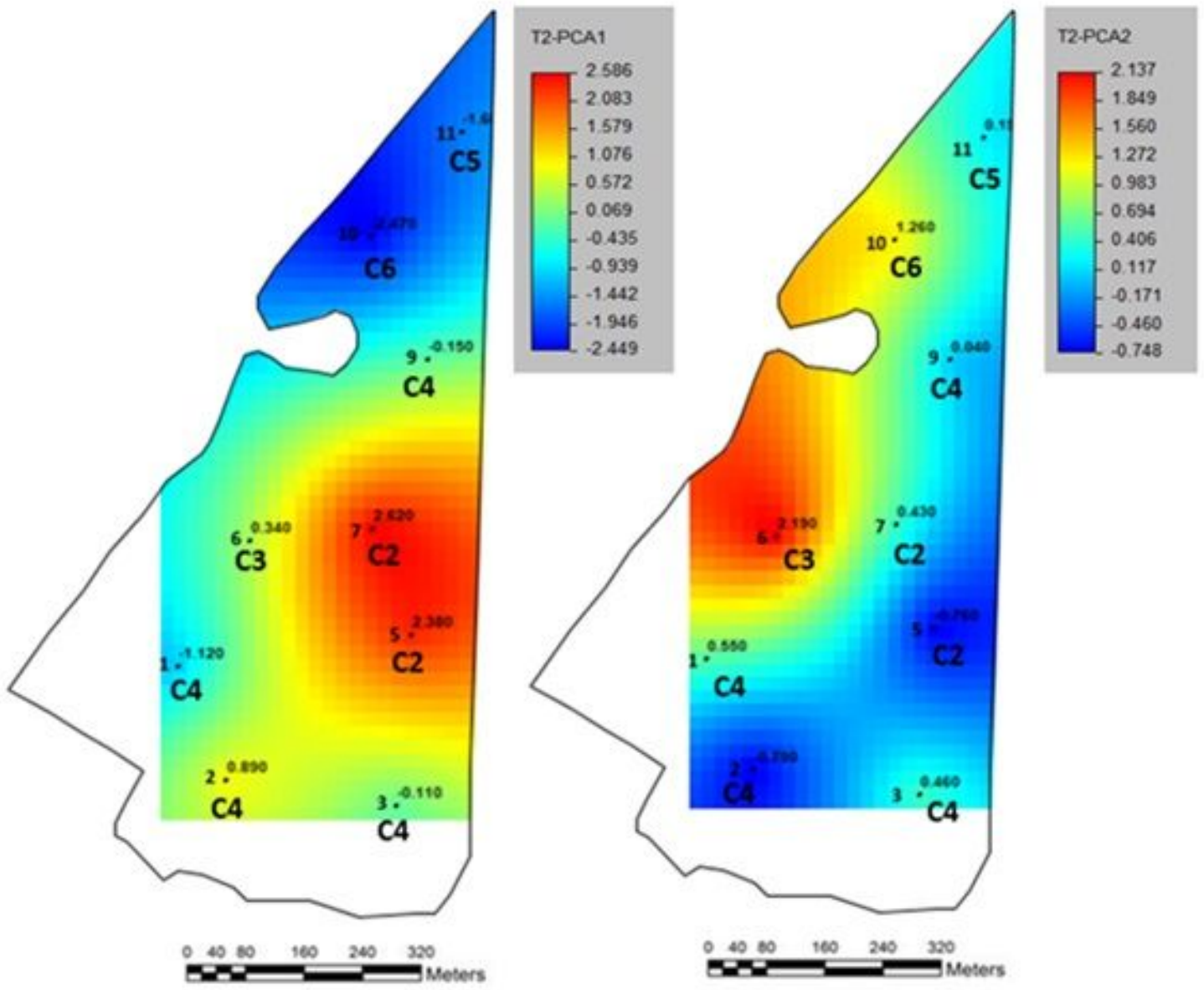

Figure 5 
Mapping of PCA1 and PCA2 scores for the time period T2. For a better spatial interpretation, KMC results (clusters $\mathrm{c} 1$ to $\mathrm{c} 6$ ) are also represented.

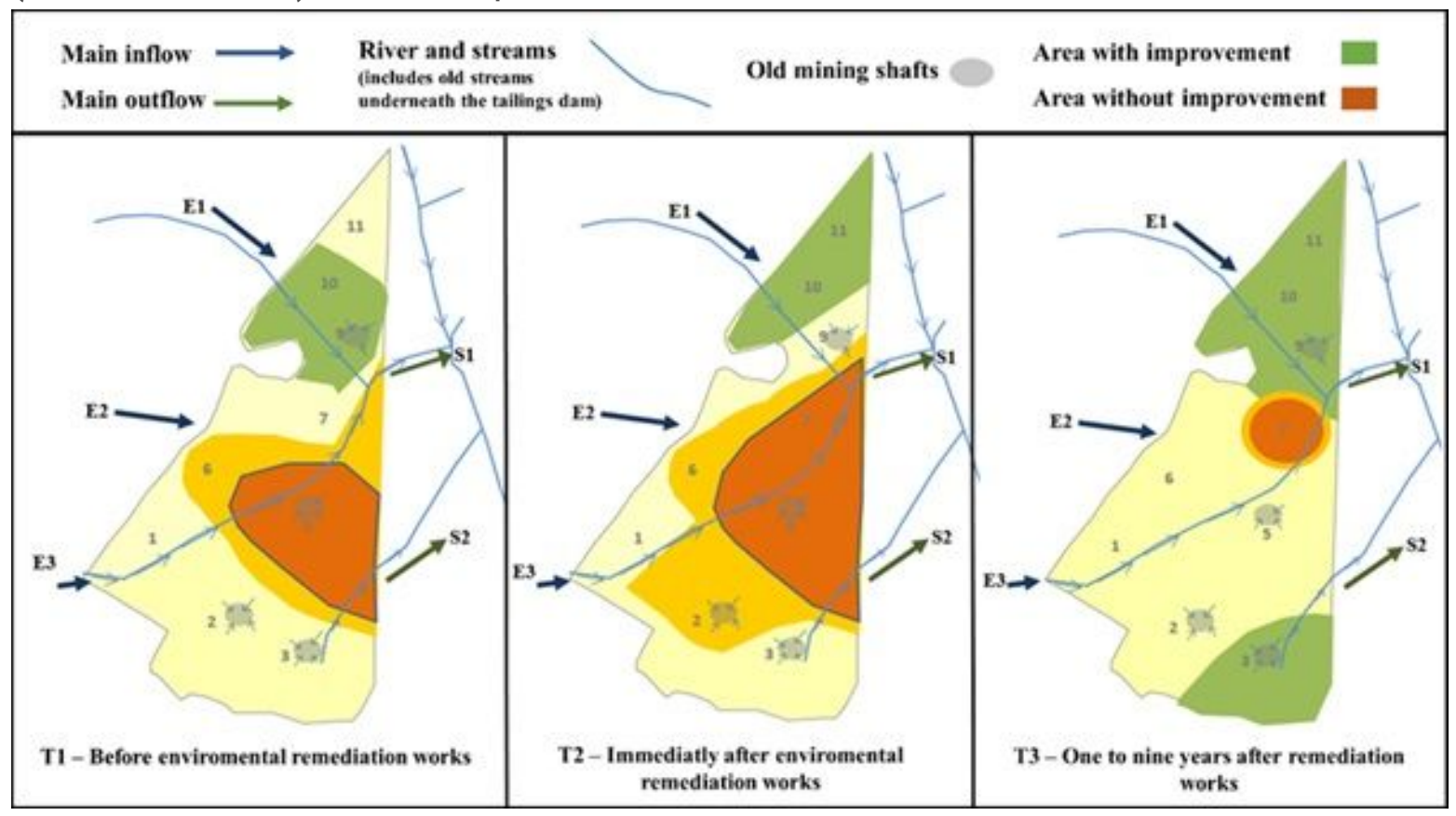

\section{Figure 6}

Interpretative maps that results from superposition of numerical groundwater models and multivariate analysis (adapted from Pinto, 2016). 